\title{
Changes in human colonic mucosal-submucosal blood flow after body surface cooling
}

\author{
D W FORRESTER, * J S DAVISON, V A SPENCE, AND W F WALKER
}

From the Departments of Surgery and Medical Physics, Ninewells Hospital and Medical School, Dundee, and the Department of Physiology, The University, Dundee

SUMmaRY Mucosal-submucosal blood flow in the human colostomy was measured by a radioisotopic washout technique. Changes in blood flow were recorded in 10 subjects after peripheral vasoconstriction evoked by surface cooling of the body. Accompanying the vasoconstriction was a rise in mucosal-submucosal blood flow of approximately $40 \%$. An interpretation of the blood flow changes and the associated alterations in mean arterial blood pressure provide evidence for vasomotor and local regulatory control in the colostomy microcirculation. We believe, therefore, that the colostomy is a suitable preparation for studying the human colonic microcirculation.

Measurement of temperature change in the human colostomy during physiological and pharmacological stimulation was considered by Grayson $^{12}$ to be an index of local colonic blood flow. In particular, Grayson ${ }^{2}$ demonstrated that a peripheral vasoconstriction evoked by surface cooling of the body produced an increased temperature in the bowel. He attributed this to a rise in colonic blood flow caused by alterations in blood pressure. Subsequently, Grayson ${ }^{3}$ showed that the relationship between tissue temperature and perfusion was not linear and hence his method could not provide a quantitative estimation of blood flow. For this reason studies of intestinal blood flow on the human colostomy gradually declined.

Recently, we have described a method for the measurement of colonic mucosal-submucosal blood flow (M-SBF) in conscious man. ${ }^{45}$ The basis of this technique is to measure the rate of removal of a freely diffusible indicator ${ }^{(125} \mathrm{I}-4$ iodoantipyrine) injected into the submucosa of a colostomy.

The purpose of the present study was to measure the quantitative changes in colonic blood flow, brought about by surface cooling of the body and, following the original work of Grayson, to re-establish the colostomy as a suitable preparation for investigating the factors which

*Address for reprint requests: D W Forrester, Department of Surgery, Ninewells Hospital and Medical School, Dundee DD1 9SY, UK.

Received for publication 30 December 1980 control the colonic mucosal-submucosal microcirculation in man.

\section{Methods}

The technique of blood flow measurement and its theoretical basis have recently been described in detail. ${ }^{5}$ Briefly, $20 \mu \mathrm{l}(3-5 \mu \mathrm{Ci})$ of a stable preparation of ${ }^{125}$ I-labelled-4-iodoantipyrine ${ }^{6}$ were injected into the submucosa of the colostomy, and the gamma-emission recorder by a collimated scintillation counter, coupled to a rate-meter and logarithmic recorder. Blood flow was calculated according to $\operatorname{Kety}^{7} 8$ from the slope of the resulting washout in terms of $\mathrm{ml} / \mathrm{min}$ per $100 \mathrm{~g}$ of tissue.

Experiments were carried out on 10 volunteers, who had had colostomies performed after intestinal resection for carcinoma of the colon or rectum. The mean age of the subjects was 59 years. The ages of the colostomies varied between one month and 12 years. The unclothed subjects lay in the supine position covered by blankets for a stabilisation period of 30 minutes. The temperature of the left index finger, taken to be representative of skin blood flow, and core temperature, measured from the colonic lumen $6 \mathrm{~cm}$ proximal to the colostomy, were monitored by two thermistors coupled to a calibrated voltmeter. In addition to temperature recordings, blood flow measurements were made on the left hand of two subjects by use of a mercury strain gauge plethysmograph. This was done to demon- 
strate a positive relationship between a fall in skin temperature and a decrease in hand blood flow indicative of cutaneous vasoconstriction. Blood pressure was measured by auscultation of the right brachial artery.

An initial measurement of blood flow was recorded after the stabilisation period. On completion of the washout a second injection of ${ }^{125}$ I-4-iodoantipyrine was made into the colostomy and, simultaneously, the subject was exposed to an environmental temperature of $20 \pm 1^{\circ} \mathrm{C}$. Additionally, the right forearm was immersed in water at $15^{\circ} \mathrm{C}$. A second washout was completed. The right arm was then removed from the water bath, dried, and the subject covered again with blankets until stabilisation was again achieved. Finally, a third measurement of $\mathrm{M}-\mathrm{SBF}$ was carried out.

During both the initial and final stabilisation periods skin and core temperatures and blood pressure were recorded at five minute intervals and repeated at one minute intervals during the cooling period.

The flow resistance per $100 \mathrm{~g}$ of mucosalsubmucosal tissue $\left(\mathrm{PRU}_{100}\right)$ was calculated for each subject, before, during, and after cooling. The resistance is equal to the pressure gradient across the colostomy vasculature $(\mathrm{mmHg})$ divided by the local blood flow $(\mathrm{ml} / \mathrm{min}$ per $100 \mathrm{~g}){ }^{9}$ Accurate determination of the pressure gradient is, however, impossible without recourse to invasive means and therefore mean brachial arterial blood pressure, estimated from the formula $\mathrm{MAP}=(\mathrm{S}+2 \mathrm{D}) / 3$, where $\mathrm{S}$ and $\mathrm{D}$ are the systolic and diastolic pressures, was considered to be the only ethically acceptable, non-invasive alternative. Using this substitution, some loss of accuracy has to be accepted in calculating regional flow resistance.

Permission for these studies was granted by the Isotope Advisory Panel, Department of Health and Social Security, Hannibal House, London, and by the local Ethical Subcommittee, Tayside Health Board, Dundee. The experiments were performed with the knowledge and consent of each subject.

\section{Results}

Values for M-SBF and mean arterial blood pressure before, during and after cooling, are listed in the Table, and shown graphically in Fig. 1. During the initial stabilisation period and throughout the resting blood flow recording, skin temperature, measured on the left index finger, remained constant (within $\pm 0.1^{\circ} \mathrm{C}$ ) in all subjects. A fall in skin temperature was observed in every subject $\left(\Delta \mathrm{T}=2 \cdot 8 \pm 1 \cdot 4^{\circ} \mathrm{C}, \mathrm{SD}\right)$ on exposure to room temperature and on cooling of the right forearm (Fig. 1). Core temperature remained constant throughout the cooling period. Evidence that the fall in skin temperature was due solely to a peripheral vasoconstriction is emphasised by plethysmographic recordings in two subjects, where there was a substantial decrease in skin blood flow (Fig. 2).

Peripheral vasoconstriction led to an immediate rise in mean arterial blood pressure and a significant rise in M-SBF of approximately $40 \%$. In two subjects, the pressure increase was only transient, returning to the initial level before the blood flow recording started. In four subjects the initial increased pressure declined throughout the blood flow recording period, although the raised blood flow remained constant (Fig. 3). In one subject, blood pressure and blood flow recovered simultaneously. The remaining three subjects had a raised arterial pressure, which was sustained throughout the cooling period.

The calculated $P R U_{100}$ fell in every subject as a result of cooling.

On rewarming, skin temperature and skin

Table Mean arterial blood pres'ure (MAP), mucosal-submucosal blood flow (M-SBF), and calculated flow resistance per $100 \mathrm{~g}$ of mucosal-submucosal tissue $\left(P R U_{100}\right)$ in 10 subjects before, during, and after cooling

\begin{tabular}{|c|c|c|c|c|c|c|c|c|c|}
\hline \multirow[t]{2}{*}{ Subject } & \multicolumn{3}{|c|}{$M A P(m m H g)$} & \multicolumn{3}{|c|}{$M-S B F(\mathrm{ml} / \mathrm{min} / 100 \mathrm{~g})$} & \multicolumn{3}{|l|}{$P R U_{100}$} \\
\hline & $\begin{array}{l}\text { Pre- } \\
\text { cooling }\end{array}$ & $\begin{array}{l}\text { During } \\
\text { cooling }\end{array}$ & $\begin{array}{l}\text { Post- } \\
\text { cooling }\end{array}$ & $\begin{array}{l}\text { Pre- } \\
\text { cooling }\end{array}$ & $\begin{array}{l}\text { During } \\
\text { cooling }\end{array}$ & $\begin{array}{l}\text { Post- } \\
\text { cooling }\end{array}$ & $\begin{array}{l}\text { Pre- } \\
\text { cooling }\end{array}$ & $\begin{array}{l}\text { During } \\
\text { cooling }\end{array}$ & $\begin{array}{l}\text { Post- } \\
\text { cooling }\end{array}$ \\
\hline 1 & 120 & $133 \cdot 3$ & 130 & $23 \cdot 1$ & $35 \cdot 4$ & $30 \cdot 1$ & $5 \cdot 2$ & 3.8 & $4 \cdot 3$ \\
\hline 2 & 105 & $111 \cdot 6$ & $101 \cdot 6$ & $36 \cdot 5$ & $49 \cdot 5$ & $23 \cdot 1$ & 2.9 & $2 \cdot 3$ & $4 \cdot 4$ \\
\hline 3 & $106 \cdot 6$ & 140 & $118 \cdot 3$ & $25 \cdot 0$ & $45 \cdot 3$ & 40.0 & $4 \cdot 3$ & $3 \cdot 1$ & $3 \cdot 0$ \\
\hline 4 & 100 & 100 & $93 \cdot 3$ & $25 \cdot 6$ & $34 \cdot 7$ & $21 \cdot 7$ & 3.9 & 2.9 & $4 \cdot 3$ \\
\hline 5 & $83 \cdot 3$ & $106 \cdot 6$ & $86 \cdot 6$ & 16.9 & $27 \cdot 7$ & $17 \cdot 2$ & 4.9 & $3 \cdot 8$ & $5 \cdot 0$ \\
\hline 6 & $73 \cdot 3$ & $83 \cdot 3$ & $76 \cdot 6$ & $10 \cdot 8$ & $13 \cdot 3$ & $10 \cdot 3$ & $6 \cdot 8$ & $6 \cdot 3$ & $7 \cdot 4$ \\
\hline 7 & 118 & 130 & 120 & $39 \cdot 3$ & $49 \cdot 5$ & 38.9 & $3 \cdot 0$ & $2 \cdot 6$ & $3 \cdot 1$ \\
\hline 8 & 99 & $109 \cdot 3$ & $106 \cdot 6$ & $30 \cdot 0$ & $49 \cdot 5$ & $35 \cdot 9$ & $3 \cdot 3$ & $2 \cdot 2$ & $3 \cdot 0$ \\
\hline 9 & $103 \cdot 3$ & $103 \cdot 3$ & 110 & $16 \cdot 5$ & $20 \cdot 1$ & $14 \cdot 1$ & $6 \cdot 3$ & $5 \cdot 1$ & $7 \cdot 8$ \\
\hline 10 & 71 & 79 & $72 \cdot 3$ & $32 \cdot 2$ & $38 \cdot 5$ & $18 \cdot 7$ & $2 \cdot 2$ & $2 \cdot 1$ & 3.9 \\
\hline
\end{tabular}


A

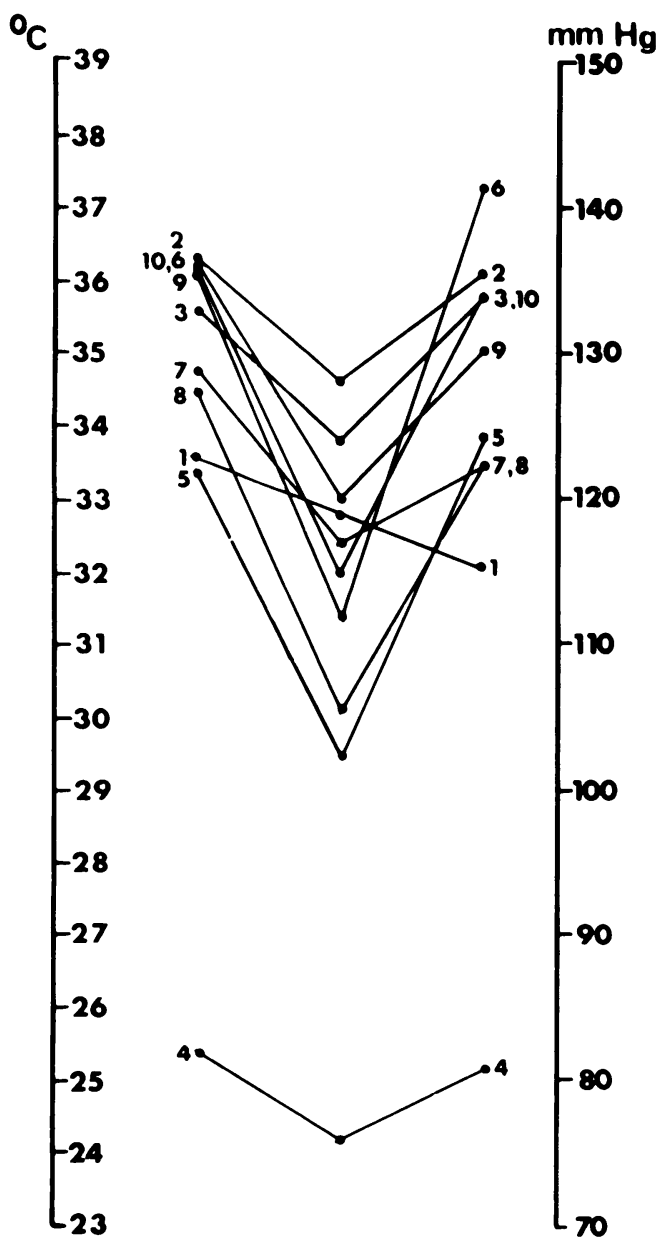

B

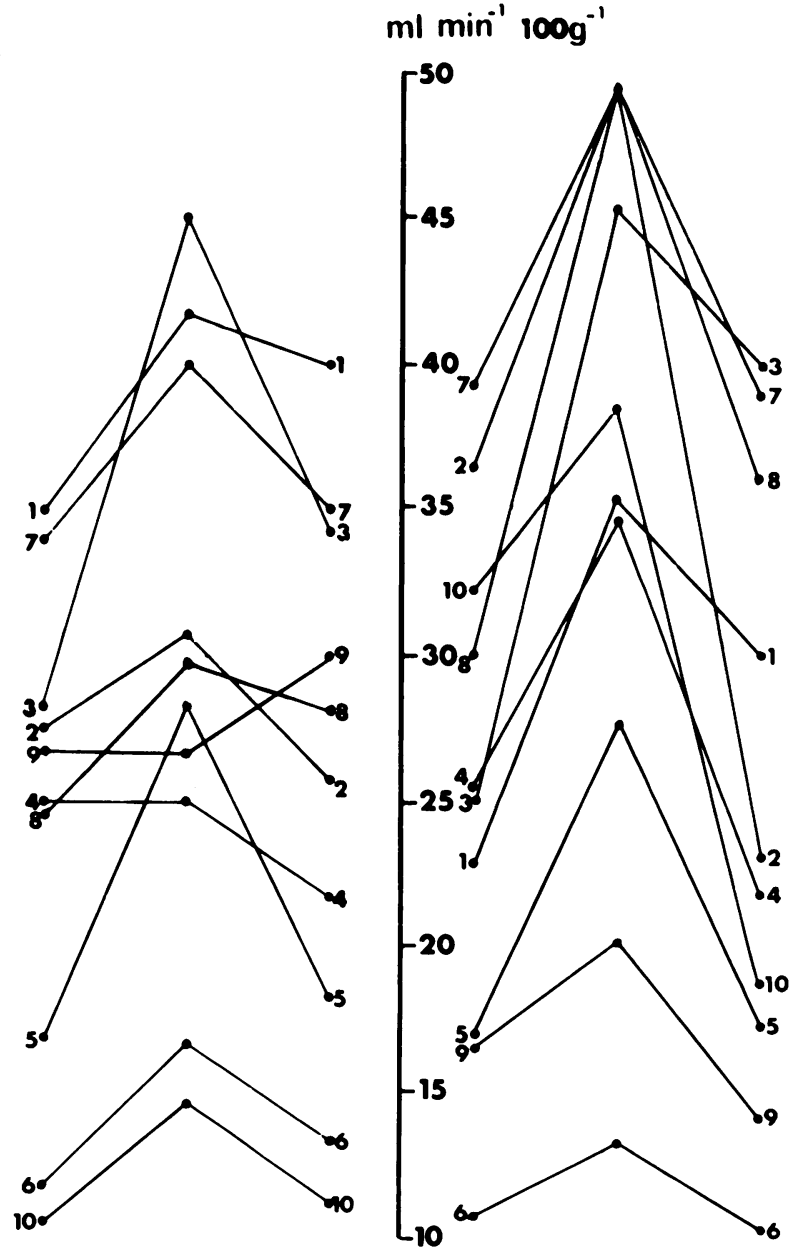

Fig. 1 Skin temperature of the left index finger $(A)$, mean arterial blood pressure $(B)$, and mucosalsubmucosal blood flow $(C)$ measured in 10 subjects, before, during and after cooling.

blood flow gradually returned to precooling values. In general, mean arterial blood pressure decreased but in eight subjects recovery of pressure was only partial. Conversely, in six subjects M-SBF recovered to values below the initial precooling level.

The calculated $P R U_{100}$ increased in nine subjects, reaching a higher value than the resting level in five of these individuals.

\section{Discussion}

The present study is one of the first to investigate colonic M-SBF in conscious man. The method used has previously been shown to provide quantitative reproducible results of blood flow."
However, the use of the colostomy as a representative segment of the normal intestinal tract may be questioned. Anatomically, it is exteriorised on to the abdominal wall, thereby exposing the mucosa to an environment which may lead to its atrophy over a period of time. Furthermore, nervous or vascular anastomoses are likely to occur between the circulations of the ageing colostomy and the skin, the effects of which could modify its physiological response. Grayson, ${ }^{3}$ however, showed that the increase in colostomy temperature, associated with peripheral cooling, was accompanied by a slight fall in the surrounding skin temperature, suggesting that the colostomy was free from the influence of cutaneous vasomotor innervation. Nevertheless. 


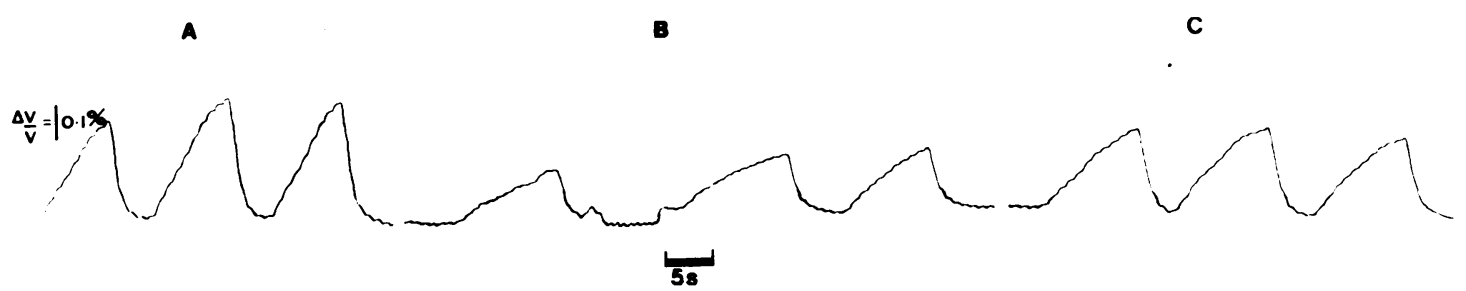

Fig. $2 A$ record of hand blood flow measured by a strain gauge plethysmograph before (A), during (B), and after $(C)$ cooling (subject 7). Blood flow is seen to decrease during the cooling period.

it is our experience that, on rare occasions, when the indicator is injected near to the mucosalcutaneous junction of a long-standing colostomy, the subject may sense some pain. While this evidence of invasion by cutaneous sensory nerves does not necessarily imply an invasion by cutaneous vasomotor nerves, it was considered prudent to avoid such a potential complication. Thus, in each case, the isotope was deposited centrally in the colostomy as remote from the mucosal-cutaneous junction as luminal access would allow. Moreover, this central area, being constantly shielded by a layer of mucus, is less likely to undergo atrophy than the more exposed peripheral parts of the mucosa; it is also the area most distant from the possible effects of operative trauma.

The study of these subjects may also be formidable, because many are advanced in age and frequently have malignant pathology. For these reasons they are often concerned and apprehensive about investigation for the purposes of research. In such circumstances it is often difficult for them to co-operate fully within the experimental framework. Nevertheless, with careful patient selection, and despite the limitations imposed by ethical considerations previously referred to in the methods section, the colostomy offers an excellent opportunity to study intestinal blood flow and its physiological control in conscious man.

Beaumont ${ }^{10}$ first recorded changes in human gastric mucosal colour as an index of blood flow. Analogous studies in colostomies by Grace et al.$^{11}$ and Friedman and Snape ${ }^{12}$ showed that psychic stimuli profoundly influenced their colour. Grayson $^{1}$ turned his attention to recording changes in colostomy temperature using fine gauge needle thermocouples. $\mathrm{He}$ assumed that changes in blood flow would alter the temperature of the colostomy when it was exposed to an environmental temperature different from that of blood. Subsequently, Grayson ${ }^{2}$ showed that heating and cooling the body produced opposite responses in the colostomy respectively, and suggested that these responses were fundamental to the peripheral regulation of blood pressure. In addition, he showed that these reactions were also

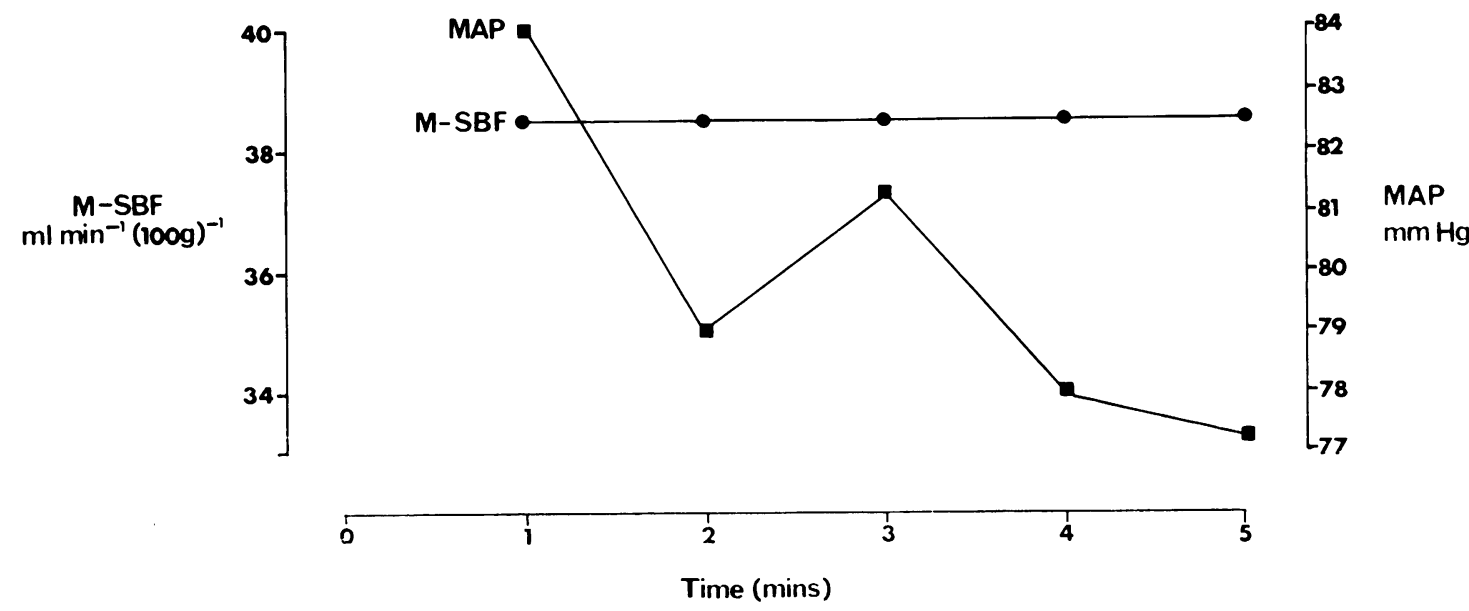

Fig. 3 Mean arterial blood pressure (MAP) and mucosal-submucosal blood flow (M-SBF) measured during the cooling period (subject 10). The raised blood flow is maintained against a fall in mean arterial pressure. 
demonstrable in the intact rectum, measured by an electrically heated thermocouple. ${ }^{3}$ From these results, Grayson implied that the colostomy had a normal innervated microcirculation, as its response to cooling simulated the response in the intact rectum.

In our experiments skin vasoconstriction on cooling was accompanied by an increase in colonic mucosal-submucosal blood flow, associated in most cases, with a raised mean arterial blood pressure. The possibility of the increased blood flow being the passive consequence of an increased perfusion pressure rather than a reflex compensatory vasodilatation should be considered. However, our results show a distinct fall in the estimated regional flow resistance, which would indicate, therefore, a vasodilatation. It is also possible that these changes in resistance might be due to passive distension of the mucosalsubmucosal vessels by the increased transmural pressure. However, at 'normal' arterial blood pressures there do not appear to be any reports of pressure-induced distension of vessels, as an increased transmural pressure would automatically be counteracted by myogenic mechanisms and the regional flow resistance would remain unaltered. The observed fall in regional flow resistance is therefore a strong indication of active vasodilatation. In addition, there were other indications of active vasodilatation, the most positive being in the two subjects (4 and 9) in whom the murosal-submucosal blood flow was seen to increase without any rise in mean arterial blood pressure. In fact, both these subiects did have a transient increase in mean arterial pressure, but, unlike the other subjects, this returned to normal by the start of the blood flow measurement period. Furthermore, in another four subjects $(1,6,7$, and 10$)$, there was a partial recovery of mean arterial blood pressure despite continued skin vasoconstriction, and in these cases the raised colonic mucosalsubmucosal blood flow remained constant over the whole of the recorded period. This suggests some compensatory vasodilatation enabling the increased colonic blood flow to be maintained against a fall in perfusion pressure. Indeed, it is likely that it was this vasodilatation which contributed to the partial restoration of blood pressure. It is in these cases, where increased mucosal-submucosal blood flow was seen to be, to some extent, independent of blood pressure that additional supportive evidence is provided for the existence of vasomotor control of the mucosalsubmucosal microcirculation of the human colostomy.
On rewarming the subjects, there was a fall in mucosal-submucosal blood flow in most cases to values below the control levels, associated with a rise in regional flow resistance. For the reasons outlined above, this would suggest an active vasoconstriction rather than the passive consequence of a fall in pressure and reduced distension. This is particularly so in subjects 9 and 10 , and, to a lesser extent, in subjects 5,6 , and 7 , where the estimated regional flow resistance increased above resting levels even though the blood pressure remained slightly raised or at least had fallen no further than precooling levels. This probably represents a compensatory vasoconstriction consequent upon the preceding hyperaemia, possibly the result of a reduction in the concentration of local vasodilator metabolites. Thus, there also appears to be an effective local regulatory mechanism in the mucosal-submucosal microcirculation of the human colostomy.

Our experience, therefore, suggests that the colostomy might be profitably used for more detailed studies of physiological control and for the study of pharmacologically induced changes in the mucosal-submucosal microcirculation.

This work was supported by grants from the Scottish Home and Health Department and the Wellcome Trust.

\section{References}

${ }^{1}$ Grayson J. Vascular reactions in the human intestine. J Physiol 1949; 109:439-47.

${ }^{2}$ Grayson J. Observations on blood flow in human intestine. Br Med J 1950; 2:1465-70.

"Grayson J. The measurement of intestinal blood flow in man. $J$ Physiol 1951; 114:419-34.

${ }^{4}$ Forrester DW, Spence VA, Walker WF. Measurement of mucosal-submuccsal blood flow in human colon. Gut 1979; 20:A447.

${ }^{5}$ Forrester DW, Spence VA, Walker WF. The measurement of colcn:c muco al-submucosal blood flow in man. J Physiol 1980; 299:1-11.

"Forrester DW, Spence VA, Bell I, Hutchinson F, Walker WF. The preparation and stability of radioiodinated antipyrine for use in local blood flow determinations. Eur J Nucl Med 1980; 5:145-6.

'Kety SS. Measurement of regional circulation by the local clearance of radioactive sodium. Am Heart $J$ 1949; 38:321-8.

${ }^{8}$ Kety SS. The theory and applications of the exchange of inert gas at the lungs and tissues. Pharmacol Rev 1951; 3:1-41.

${ }^{9}$ Folkow B, Neil E. Circulation. New York: Oxford University Press, 1971: 18.

${ }^{10}$ Beaumont W. Experiments and observations on the gastric juice and the physiology of digestion. Facsimile of the original edition of 1833. Cambridge: Harvard University Press, 1929. 
${ }^{11}$ Grace WJ, Wolf S, Wolff HG. The human colon New York: Hoeber Medical Division, Harper and Row, 1951.
${ }^{12}$ Friedman MHF, Snape WJ. Color changes in the mucosa of the colon in children as affected by food and psychic stimuli. Fed Proc 1946; 5:30-1. 